\title{
Un-Retrieved Deformed Biodegradable Polymer Coated Drug Eluting Stent after Percutaneous Coronary Intervention to Complete Occluded Right Coronary Artery: Patient at 8 Months Angiographic Follow-Up
}

\author{
Layth A. Mimish \\ Department of Medicine/Cardiovascular Unit, King Abdulaziz University, Jeddah, KSA \\ Email: layth mimish@hotmail.com
}

Received 8 January 2014; revised 4 February 2014; accepted 1 March 2014

Copyright (C 2014 by author and Scientific Research Publishing Inc.

This work is licensed under the Creative Commons Attribution International License (CC BY).

http://creativecommons.org/licenses/by/4.0/

(c) (†) Open Access

\begin{abstract}
Balloon rupture during stent deployment is rare, and can cause stent damage upon its retrieval. We described a case of inadequate drug-eluting stent expansion in a fibrotic and calcified mid right coronary artery lesion despite pre-treatment with high pressure balloon inflation, with rupture and entrapment of the balloon within the stent. Attempts of retrieval of the ruptured balloon caused severe deformity of the distal segment of the stent. The stent could not be crushed or retrieved, and was left in situ. Angiographic follow-up at 8 months time showed widely patent vessel.
\end{abstract}

\section{Keywords}

Stent Entrapment; Balloon Rupture; Deformed Stent

\section{Introduction}

Despite safety of new low profile, factory crimped drug-eluting stent (DES) and the pre-dilatation of calcified fibrotic lesions prior to stent deployment, stent expansion may be inadequate, and balloon rupture and entrapment can occur in those lesions [1]-[3]. In most of the cases, the ruptured balloon causes no significant adverse effects and can be retrieved easily, but it may cause major dissection, vessel perforation or rupture, myocardial infarction or death [4] [5]. In case of balloon entrapment and for slipped stents, broken wires or angioplasty products, multiple techniques for their retrieval have been described to decrease the risk of thrombosis by pre- 
venting foreign body remnants in the coronary tree [6]-[11]. Emergency surgery may be required if percutaneous techniques fail. In this case, we describe a case of rupture and entrapment of the balloon within the stent. Attempts of retrieval of the ruptured balloon caused severe deformity of the distal segment of the stent. The stent could not be crushed or retrieved, hence left in situ. Angiographic follow-up at 8 months time showed widely patent vessel.

\section{Case Report}

A 65-year-old male was admitted with acute coronary syndrome (ACS), Canadian cardiovascular society (CCS) class IV angina, of 2 week duration, with atherosclerotic risk factors such as age, hypertension, diabetes mellitus of 20 year duration, hyperlipidemia of 14 year duration, and smoking.

He had history of ischemic heart disease (IHD), limited inferior wall myocardial infarction (IWMI), severe triple vessel coronary artery disease (CAD), for which he underwent coronary artery bypass graft (CABG) surgery in 2004 with left internal mammary (LIMA) graft to left anterior descending (LAD) and reversed saphenous vein graft (RSVG) to obtuse marginal (OM) and posterior descending artery (PDA) of right coronary artery (RCA).

He was admitted with stable angina in 2007 and had coronary angiography showing normal left main, 100\% chronic total occlusion (CTO) of LAD, with patent LIMA graft to LAD, tight proximal left circumflex (LCx) lesion and $70 \%$ long OM lesion, with long chronic total occlusion in proximal RCA, with multiple distal RCA tight lesions seen from collaterals to distal RCA. Both vein grafts were totally occluded. He was managed with maximizing medical therapy, and remained asymptomatic until his recent presentation.

He was treated with subcutaneous enoxaparin (Clexane), intravenous (IV) tirofiban (Aggrastat), IV nitroglycerin and clopidogril (Plavix) $600 \mathrm{mg}$ loading dose. His vitals were normal. His 12-lead electrocardiogram showed normal sinus rhythm, old IWMI, and 2-dimensional echocardiogram showed left ventricular ejection fraction (LVEF) of 55\% with mild diaghragmatic hypokinesia.

His coronary angiogram was done next day, showing progression of circumflex artery lesion to subtotal occlusion, tighter OM lesion, and more sluggish flow to distal RCA, with patent LIMA graft (Figure 1).

The LCx/OM lesions were dilated, and then implanted with two overlapping $2.5 \times 20 \mathrm{~mm}$ Supralimus-Core sirolimus-eluting biodegradable polymer coated cobalt-chromium stents (Sahajanand Medical Technologies Pvt. Ltd., India). The lesion was post dilated with $3 \times 15 \mathrm{~mm}$ HPB Avance (Avance Medical, USA) with good final results (Figure 2).

The RCA was completely occluded chronically. The RCA lesion was crossed with some difficulty with 0.014 high standard wires, which stopped before the crux. It was dilated with $1.25 \mathrm{~mm}$ balloon, which was used to support the wire to cross the distal RCA occlusion. The multiple lesions in RCA were gradually dilated with 1.5, 2.0, and then $2.5 \mathrm{~mm}$ Avance high-pressure balloon (HPB) (Figure 3).

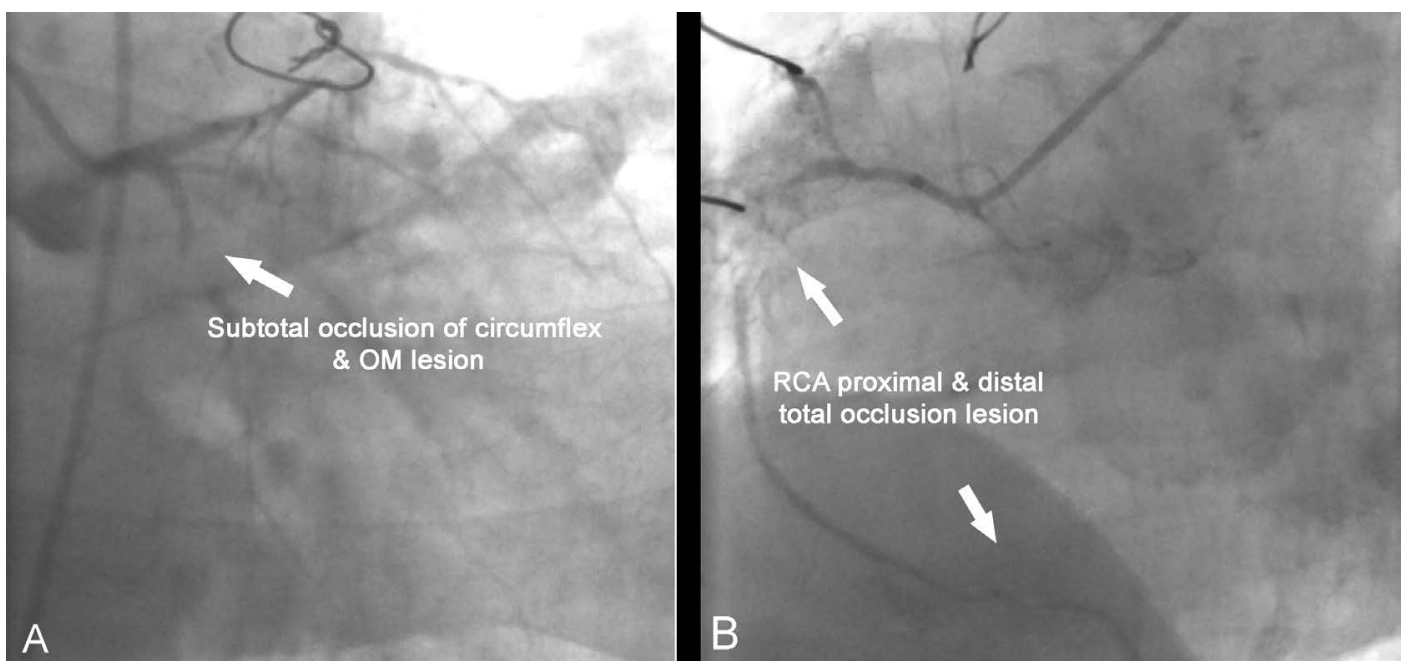

Figure 1. Angiogram of (A) left coronary artery and (B) right coronary artery. 


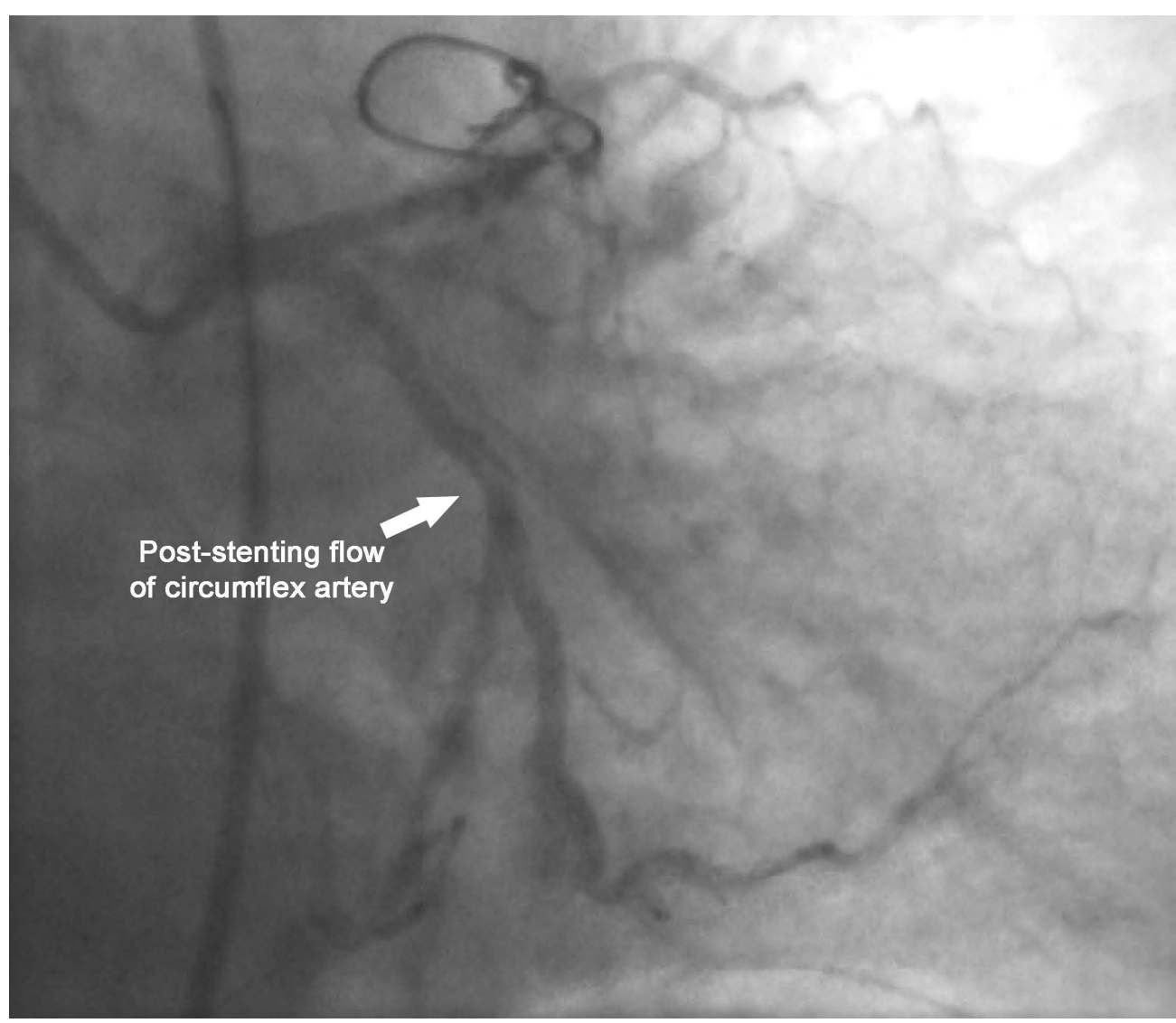

Figure 2. Post-stenting angiogram of circumflex artery.

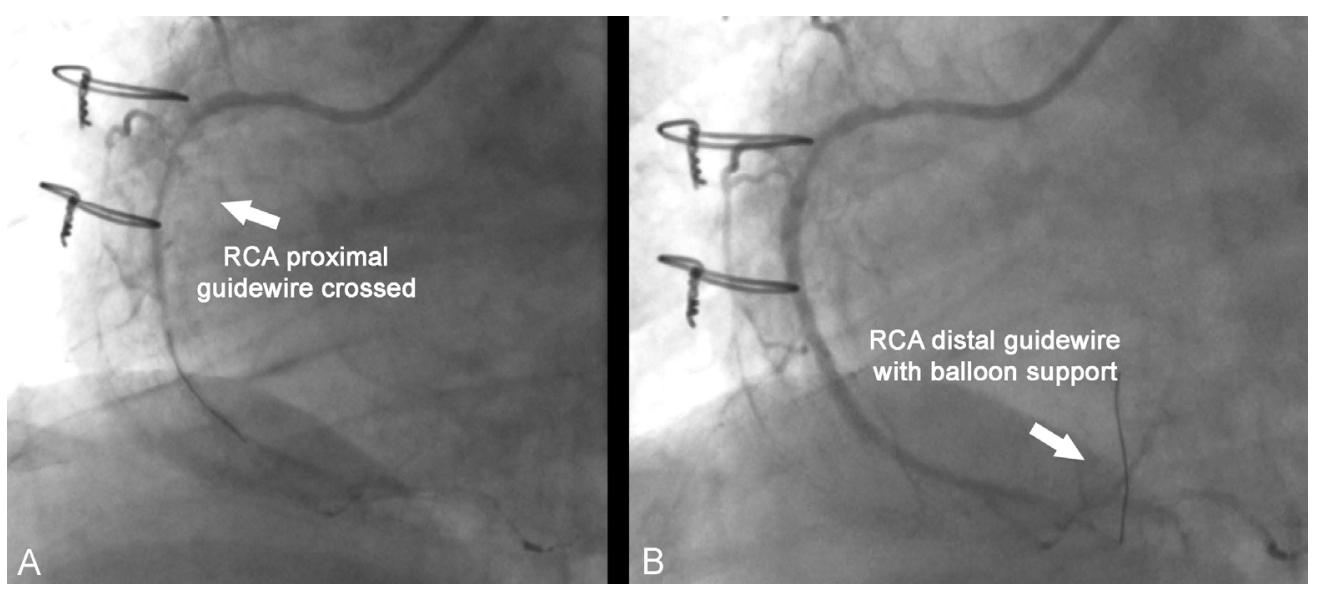

Figure 3. (A) Proximal CTO crossed but fail to cross distal CTO; (B) Distal RCA crossed with balloon support and dilatation.

The mid RCA long lesion was stented with $2.5 \times 36 \mathrm{~mm}$ long Supralimus-Core stent deployed at 16 atmospheres (atm). It was noted that the distal stent was not fully expanded, at a calcified site despite pre-dilatation with HPB (Figure 4).

The decision was to deploy a proximal stent first then dilate both stents with HPB. A proximal stent was deployed successfully at $16 \mathrm{~atm}$. A HPB (Avance $2.5 \times 15 \mathrm{~mm}$ ) was crossed easily through distal stent and inflated, but ruptured at $18 \mathrm{~atm}$ (RBP $20 \mathrm{~atm}$ ), causing mild intimal dissection, and was stuck within the stent.

Attempt of rapid inflation and deflations of the balloon and advancing it did not help to free the balloon from 


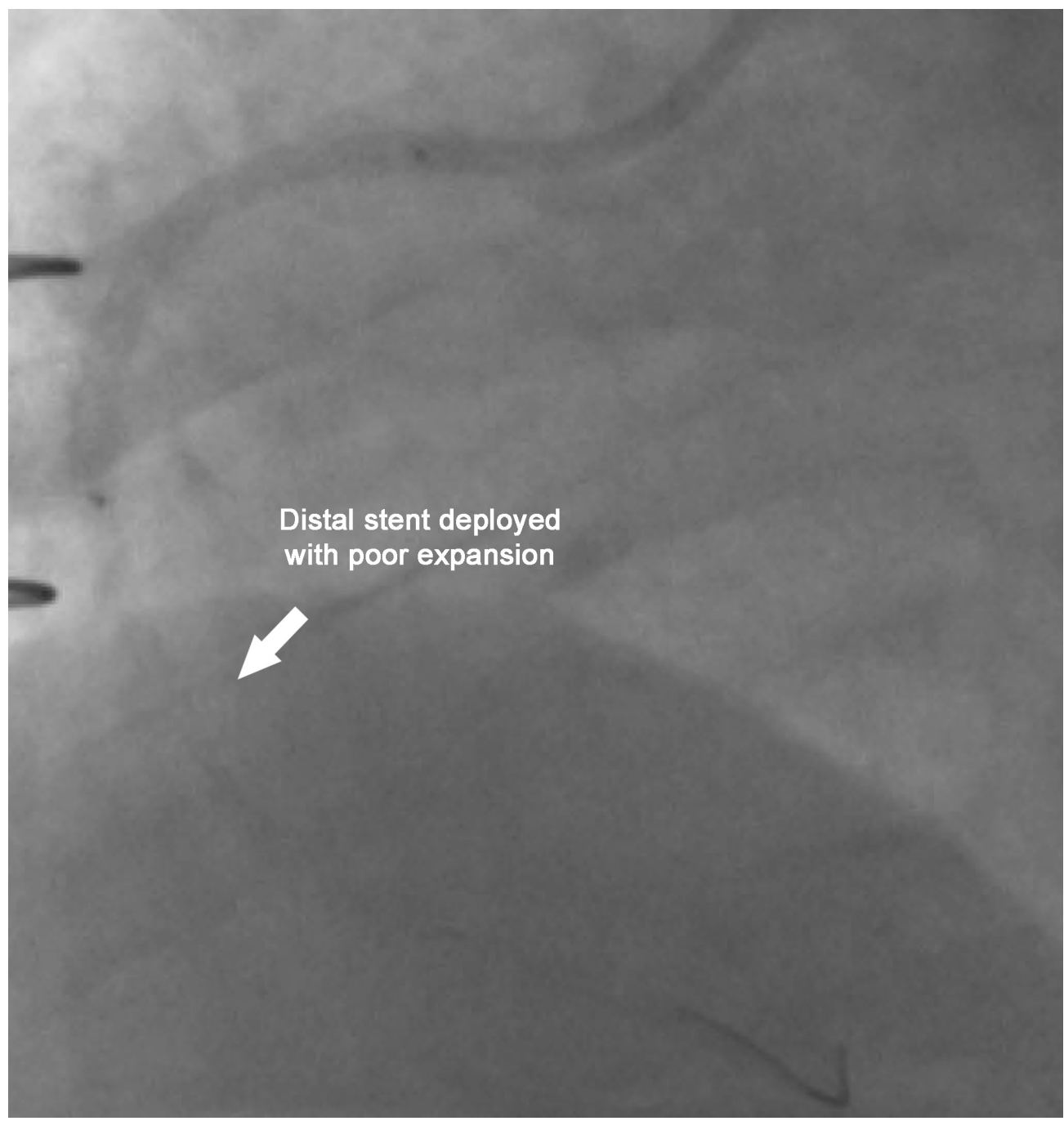

Figure 4. Distal stent deployed with poor expansion distally, and proximal stent well deployed.

the stent, and the patient was having chest pain, but hemodynamically stable. A 0.014 wire could not be passed around the ruptured balloon. With the proximal well deployed stent, the guiding catheter was deeply engaged, and the balloon was pulled back intact from the RCA, but with the wire stuck to the ruptured balloon. The chest pain subsided, and angiogram showed mild intimal dissection, the thrombolysis in myocardial ischemia (TIMI III) flow distally, but markedly deformed distal half of the distal stent (Figure 5).

The decision was to pass a wire through the deformed stent and crush it against the wall, and re-stenting the area to prevent protruding foreign body in the lumen, which may cause thrombosis. Trying to snare the deformed stent was not an option, because it may cause severe damage to the vessel, especially that the proximal part of the stent was deployed well, and the presence of proximal stent.

After multiple attempts, a 0.014 percutaneous transluminal coronary angioplasty (PTCA) wire was passed across the deformed stent to distal RCA, but several attempts to pass $1 \mathrm{~mm}$ CTO balloon Synexmed (Shenzhen) failed despite deep engagement of guiding catheter, and failure to pass another wire. The proximal part of the deformed stent and proximal stent were re-dilated again with $3 \mathrm{~mm}$ HPB, with again failure to pass another wire and $1 \mathrm{~mm}$ balloon across the deformed segment (Figure 6).

Over 45 minutes there was no change in flow, and the decision was to leave the deformed stent in situ. He was continued on Aggrastat (tirofiban) for 48 hour with subcutaneous enoxaparin, after procedure and discharged home on medical therapy. 


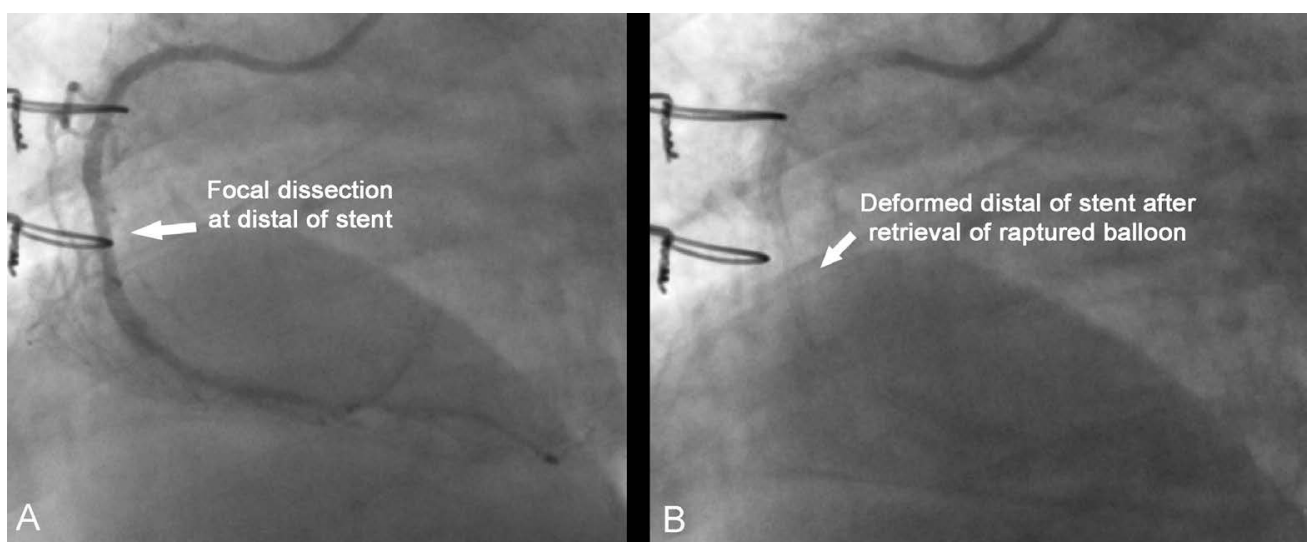

Figure 5. (A) Focal dissection at the distal of stent; (B) Deformed distal of stent after retrieval of the ruptured stent.

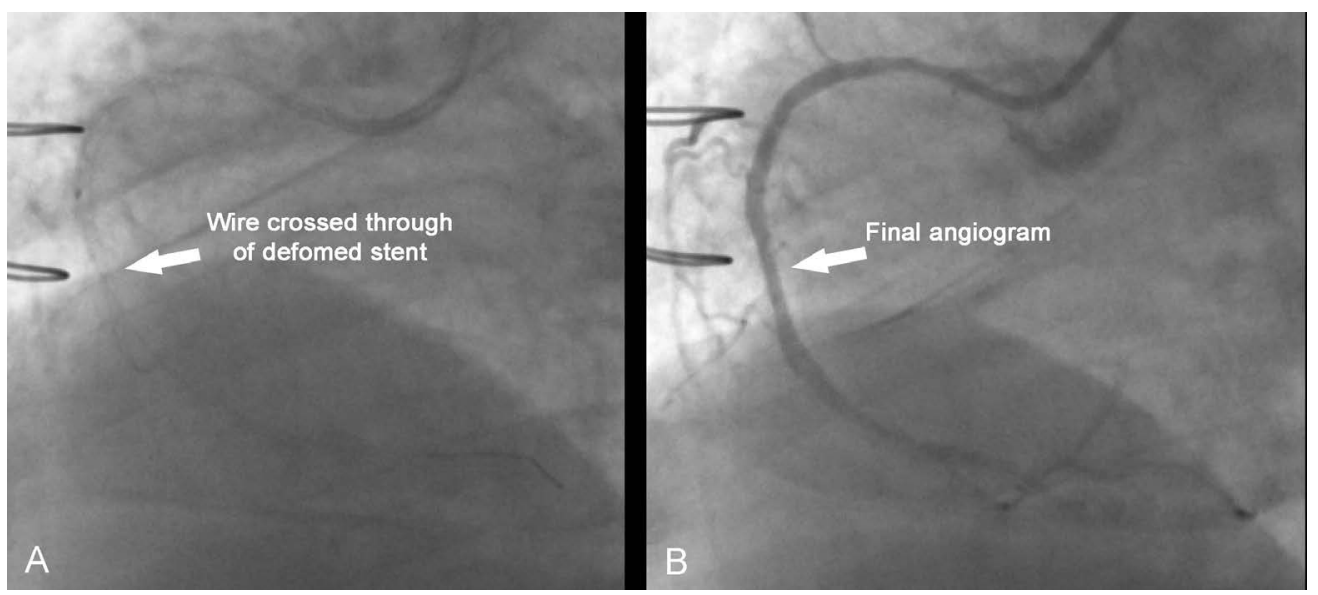

Figure 6. Wire crossed through mid-struts of deformed stent and final angiogram.

The patient was followed up regularly and remained asymptomatic. He underwent coronary angiography at 8 months, as part of ongoing study, which showed fully patent stents in LCx and RCA (Figures 7 and 8).

\section{Discussion}

Balloon rupture during PTCA has been reported in 3.6\% of cases [1]. The causes of rupture include exceeding rated burst pressure during balloon inflation, faulty manufacture, and puncture by protruded stent strut, especially true for manually crimped stents, which is rarely used now except in Szabo technique in bifurcational lesions [1]-[5]. It can occur during dilatation of a calcified lesion, or within un-evenly expanded stent, which is the most likely cause of balloon rupture in our case. This is decreased by proper preparation of the lesion by rotablator, cutting balloon, or rarely laser ablation [6]-[9], and like in our case high pressure balloon, documenting full balloon expansion prior to deployment of the stent.

Balloon rupture can be in the form of micro-perforation, longitudinal, or transverse rupture. In most of the cases, it causes no adverse sequelae, but it can lead to variable degree of intimal dissection, vessel rupture, or like in our case balloon entrapment in the vessel, or within a stent. Based on the location of the entrapped remnant, it can lead to significant hemodynamic compromise, MI, or death. It may require urgent management to prevent these complications.

Several percutaneous techniques have been described to retrieve intracoronary angioplasty catheters remenants such as broken PTCA wires, slipped stets, entrapped balloons, rotablator burrs, intravascular ultrasound catheters, and flow wires. Presence of these fragment can cause major adverse events, including vessel perforation, occlusion, or infection [10]-[14]. 


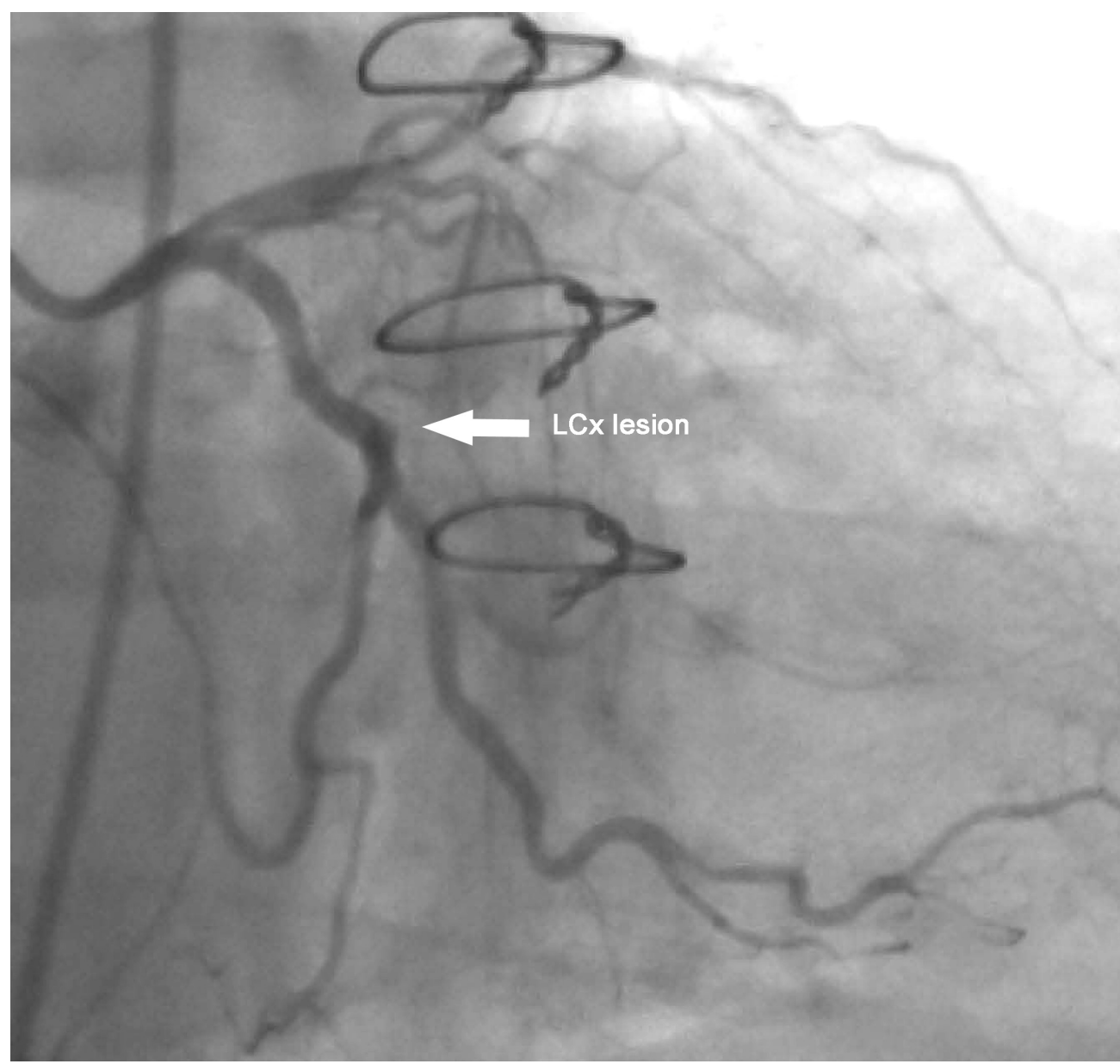

Figure 7. Angiogram of LCx at 8 months post-procedure.

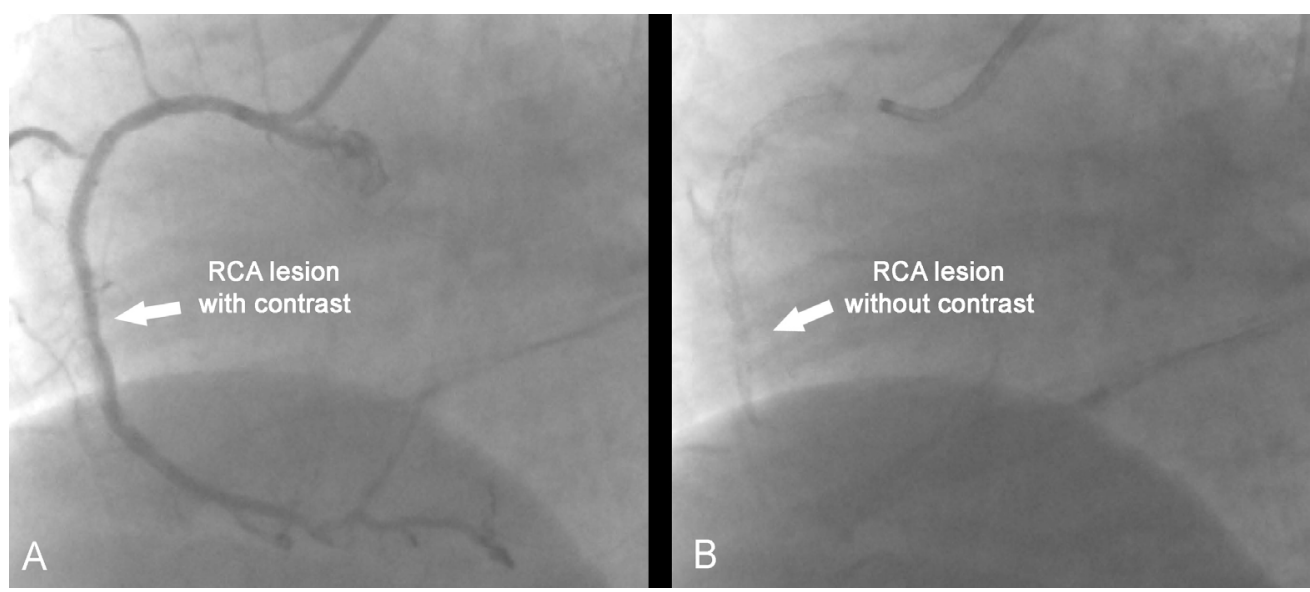

Figure 8. Angiogram of RCA at 8 months post-procedure.

These techniques vary depending on the remnant and its locations in the coronary tree as well as ease or risks of attempting to retrieve it. These techniques include the use of simple twirling of 2 PTCA, 0.014 wires to retrieve remnants of PTCA wires or slipped stents, the use of PTCA balloon to retrieve slipped stents, or free an entrapped balloon, the use of different types of snares to help catch and remove most of the lost items, and the use of bioptomes, especially if the location of the lost item is proximal in the coronary artery. For slipped or de- 
formed stent, it can be crushed by a balloon and covered by another stent.

For an entrapped balloon, the initial step is to try rapid inflation and deflation of the balloon, preferably with power injector, then trying to push the balloon forward to free it, and then pulling it back, if that fails, an attempt to inflate a balloon beside the damaged balloon to free it, if at all possible to push a wire around it. Deep engagement of the guiding catheter and pulling back the balloon forcefully may succeed, but carries the risk of vessel dissection, and fracture of the balloon shaft, which usually occurs at the site of wire exit in monorail catheters. It can also lead to underlying stent damage like in our case. For each percutaneous technique, the operator should be familiar with the device used and carefully assess risks and benefits of the procedure. Preparation of the heavily calcified or fibrotic lesion is ideal before stenting, and that is not in our center.

In our case, forceful retraction of the balloon was successful, but it caused deformity to the distal part of the stent. The usage of snaring was not the choice since the proximal part of the stent was well deployed, and it could cause major dissection at the area, and damage to the proximal stent. The option of crushing was chosen, but unfortunately the smallest balloon could not cross the deformed stent.

If all percutaneous techniques fail, then emergency coronary artery bypass surgery is needed if there is a major risk of vessel occlusion, especially with hemodynamic compromise. The incidence of emergency bypass surgery had declined dramatically from $2.9 \%$ in the pre-stent era to $0.7 \%$ in the early stent era, and $0.3 \%$ in the current stent era. Despite that, the hospital mortality of emergency surgery remained high at $10 \%-14 \%$ [15]-[18].

In our case, the patient was asymptomatic, had no change in TIMI flow in 40 minutes, and had already old partial inferior MI, and previous CABG surgery, giving a high risk for redoing surgery, so conservative therapy was elected.

Under-expansion, or deformation of coronary stent increases the chance of stent restenosis and thrombosis [19], but it is possible that the adequate blood flow around the deformed distal stent intra-luminal segment, had provided enough wash-out to prevent stent thrombosis. The follow-up angiogram showed widely patent deformed stent, which was not reported before.

\section{References}

[1] Simpfendorfer, C.C., Dimas, A.P., Zaidi, A., Hollman, J., Franco, I., Knezinek, V. and Hobbs, R.E. (1986) Balloon Rupture during Coronary Angioplasty. Angiology, 37, 828-831. http://dx.doi.org/10.1177/000331978603701106

[2] Kwan, T., Huber, M.S., Jani, H. and Feit, A. (1994) Multiple Balloon Rupture during Coronary Angioplasty. A Case Report. Angiology, 45, 891-896. http://dx.doi.org/10.1177/000331979404501009

[3] Colombo and Skinner, J.M. (1990) Balloon Entrapment in a Coronary Artery: Potential Serious Complications of Balloon Rupture. Catheterization and Cardiovascular Diagnosis, 19, 23-25. http://dx.doi.org/10.1002/ccd.1810190107

[4] Holmes, Jr., D.R., Holubkov, R., Vlietstra, R.E., Kelsey, S.F., Reeder, G.S., Dorros, G., Williams, D.O., Cowley, M.J., Faxon, D.P., Kent, K.M., et al. (1988) Comparison of Complications during Percutaneous Transluminal Coronary Angioplasty from 1977 to 1981 and from 1985 to 1986: The National Heart, Lung, and Blood Institute Percutaneous Transluminal Coronary Angioplasty Registry. Journal of the American College of Cardiology, 12, 1149-1155. http://dx.doi.org/10.1016/0735-1097(88)92593-4

[5] Steffenino, G., Meier, B., Finci, L., Velebit, V., Von Segesser, L., Faidutti, B. and Rutishauser, W. (1988) Acute Complications of Elective Coronary Angioplasty: A Review of 500 Consecutive Procedures. British Heart Journal, 59, 151-158. http://dx.doi.org/10.1136/hrt.59.2.151

[6] Li, S.S.L. and Cheng, C.W. (2004) Coronary Angioplasty on an Impassable Calcified Stenosis Using a Buddy Balloon Technique. Catheterization and Cardiovascular Interventions, 62, 35-37. http://dx.doi.org/10.1002/ccd.20005

[7] Brogan III, W.C., Popma, J.J., Pichard, A.D., Satler, L.F., Kent, K.M., Mintz, G.S. and Leon, M.B. (1993) Rotational Coronary Atherectomy after Unsuccessful Coronary Balloon Angioplasty. American Journal of Cardiology, 71, 794-798. http://dx.doi.org/10.1016/0002-9149(93)90826-X

[8] Asakura, Y., Furukawa, Y., Ishikawa, S., Asakura, K., Sueyoshi, K., Sakamoto, M., Takagi, S., Takatsuki, S., Oyamada, K. and Okabe, T. (1998) Successful Predilation of a Resistant, Heavily Calcified Lesion with Cutting Balloon for Coronary Stenting: A Case Report. Catheterization and Cardiovascular Diagnosis, 44, 420-422. http://dx.doi.org/10.1002/(SICI)1097-0304(199808)44:4<420::AID-CCD13>3.0.CO;2-M

[9] Ahmed, W.H., Al-Anazi, M.M. and Bittl, J.A. (1996) Excimer Laser-Facilitated Angioplasty for Undilatable Coronary Narrowings. American Journal of Cardiology, 78, 1045-1047. http://dx.doi.org/10.1016/S0002-9149(96)00533-4

[10] Sasseen, B.M., Burke, J.A., Shah, R., Costa, M.A., Zenni, M., Gilmore, P. and Bass, T.A. (2002) Intravascular Ultra- 
sound Catheter Entrapment after Coronary Artery Stenting. Catheterization and Cardiovascular Interventions, 57, 229-233. http://dx.doi.org/10.1002/ccd.10244

[11] Hung, C.L., Tsai, C.T. and Hou, C.J.Y. (2004) Percutaneous Transcatheter Retrieval of Retained Balloon Catheter in Distal Tortuous Coronary Artery: A Modified Double Helix Approach. Catheterization and Cardiovascular Interventions, 62, 471-475. http://dx.doi.org/10.1002/ccd.20134

[12] Eggebrecht, H., Haude, M., von Birgelen, C., Oldenburg, O., Baumgart, D., Herrmann, J., Welge, D., Bartel, T., Dagres, N. and Erbel, R. (2000) Nonsurgical Retrieval of Embolized Coronary Stents. Catheterization and Cardiovascular Interventions, 51, 432-440. http://dx.doi.org/10.1002/1522-726X(200012)51:4<432::AID-CCD12>3.0.CO;2-1

[13] Kim, M.H., Cha, K.S. and Kim, J.S. (2001) Retrieval of Dislodged and Disfigured Transradially Delivered Coronary Stent: Report on a Case Using Forcep and Antegrade Brachial Sheath Insertion. Catheterization and Cardiovascular Interventions, 52, 489-491. http://dx.doi.org/10.1002/ccd.1109

[14] Brilakis, E.S., Best, P.J., Elesber, A.A., Barsness, G.W., Lennon, R.J., Holmes, D.R., Rihal, C.S. and Garratt, K.N. (2005) Incidence, Retrieval Methods, and Outcomes of Stent Loss during Percutaneous Coronary Intervention: A Large Single Center Experience. Catheterization and Cardiovascular Interventions, 66, 333-340. http://dx.doi.org/10.1002/ccd.20449

[15] Kozman, H., Wiseman, A.H. and Cook, J.R. (2001) Long-Term Outcome Following Coronary Stent Embolization or Misdeployment. American Journal of Cardiology, 88, 630-634. http://dx.doi.org/10.1016/S0002-9149(01)01804-5

[16] Seshadri, N., Whitlow, P.L., Acharya, N., Houghtaling, P., Blackstone, E.H. and Ellis, S.G. (2002) Emergency Coronary Artery Bypass Surgery in the Contemporary Percutaneous Coronary Intervention Era. Circulation, 106, $2346-2350$. http://dx.doi.org/10.1161/01.CIR.0000036595.92742.69

[17] Yang, E.H., Gumina, R.J., Lennon, R.J., Holmes, D.R., Rihal, C.S. and Singh, M. (2005) Emergency Coronary Artery Bypass Surgery for Percutaneous Coronary Interventions Changes in the Incidence, Clinical Characteristics, and Indications from 1979 to 2003. Journal of the American College of Cardiology, 46, 2004-2009. http://dx.doi.org/10.1016/j.jacc.2005.06.083

[18] Singh, J., Thingnam, S.K., Das, D., Singh, H., Sharma, R. and Vijayvergia, R. (2007) Surgical Removal of Entrapped and Broken Percutaneous Transluminal Coronary Angioplasty Balloon Catheter. Interactive Cardiovascular and Thoracic Surgery, 6, 94-96. http://dx.doi.org/10.1510/icvts.2006.140194

[19] Patterson, M. and Slagboom, T. (2006) Intracoronary Stent Dislodgment: Updated Strategy Enabled by the New Generation of Materials. Catheterization and Cardiovascular Interventions, 67, 386-390. http://dx.doi.org/10.1002/ccd.20632 